\title{
The Effect of Academic Vocabulary Use on Graduate Students' Writing Assignment Scores
}

\author{
Ahmad I. Alhojailan ${ }^{1}$ \\ ${ }^{1}$ Department of English Language and Translation, Qassim University, Buraydah, Saudi Arabia \\ Correspondence: Ahmad I. Alhojailan, Department of English Language and Translation, Qassim University, \\ Buraydah, Saudi Arabia.
}

Received: July 13, 2019 Accepted: August 5, 2019 Online Published: August 7, 2019

doi: 10.5539/elt.v12n9p33 URL: https://doi.org/10.5539/elt.v12n9p33

\begin{abstract}
Since students are increasingly expected to use academic vocabulary while at university, this study was conducted to determine whether a statistical correlation existed between the use of academic vocabulary in assignments and the marks obtained by graduate students, using a purposive sample of graduate students $(\mathrm{n}=11)$. The students were asked to provide some of their assignments and to take part in an interview. Twenty-three assignments were collected, and five students were interviewed. Textual analyses and interviews were conducted to measure correlations between variables and address other questions. To determine words that could be identified as being academic, I used the academic word list (AWL) created by Coxhead in 2000. No significant correlation was found between the use of the academic vocabulary in the assignments and the marks the students received. Additionally, this study investigated certain other variables, such as: the importance of academic vocabulary from the students' perspective, their understanding of academic vocabulary, and their attitudes towards the choice of academic vocabulary.
\end{abstract}

Keywords: academic writing, academic vocabulary, graduate, assignment, student

\section{Introduction}

Since the 1990s, the aspect of vocabulary has gained increasing attention in language education studies, and many studies have been conducted to investigate issues related to vocabulary (e.g. vocabulary learning strategies, incidental vs. intentional vocabulary learning, and differences between genders in learning vocabulary). Vocabulary was described as the "poor relation" of second language teaching and learning till the mid-1980s (Maiguashca, 1993).

Nation (2001) has divided vocabulary according to its importance into four categories. The first category is high-frequency vocabulary - words that can be found in daily speech, conversation, and basic writing - which usually makes up around $80 \%$ of any text and around $90 \%$ of conversations and novels. The second category is academic vocabulary - words between high-frequency and technical words - which occur mostly in academic texts and usually cover from $8 \%$ to $10 \%$ of running words in academic texts, $4 \%$ of newspapers, and less than $2 \%$ of the running words of novels. The third category is technical vocabulary-words used in specialized fields - which usually cover up to $5 \%$ of texts. The fourth category is low-frequency vocabulary-rarely used ones - which account for $5 \%$ of the running words in texts. This division shows that the vocabulary does not have the same level of importance, which means that some vocabulary needs more focus in certain stages of learning than others.

During the last 70 years, researchers have noted that there are certain words that appear frequently in different disciplines (Ming-tzu \& Nation, 2004). Therefore, many attempts have been made to create lists of such words. There are several major vocabulary lists in the English whose purposes vary; some examples are: Michael West's (1953) General Service List (GSL), Xue and Nation's (1984) University Word List (UWL), and Averil Coxhead's (2000) Academic Word List (AWL). Such lists, of course, are considered tools for students in learning vocabulary.

Due to the increasing number of published academic texts in English (Swales, 1990) and the increasing numbers of students (whether native or non-native speakers of English) enrolling in universities where the language of study is English (Institute of International Education, 2014), the important role of academic English is clear. 
Laufer and Nation (1999) pointed out that English for Academic Purposes (EAP) learners whose knowledge of academic vocabulary is inadequate will not be able to deal effectively with the academic materials that they are supposed to read.

\section{Literature Review}

\subsection{Differences Between Academic English and General English}

The relevant literature reveals some differences between academic English and general English. One of the important differences is the vocabulary used. Many researchers investigated this topic (e.g. Xue \& Nation, 1984; Coxhead, 2000; Coxhead \& Nation, 2001; Nation, 2001). Coxhead and Nation (2001), for example, described the features of academic vocabulary thus:

1) Academic vocabulary is mostly found in a wide range of academic texts, and is generally rare in non-academic texts.

2) Academic vocabulary represents a substantial amount of the vocabulary in academic texts.

3) Academic vocabulary, unlike the technical vocabulary, is not well known.

4) Academic vocabulary enables English teachers to help learners.

Casanave and Hubbard (1992) stated that teachers of humanities and social sciences consider the appropriateness of vocabulary use the most difficult feature in non-native student writing. Relevant in this context is the study conducted by Bush, Cadman, de Lacey, Simmons, and Thurstun (1996), whose findings showed that when the academics of four universities in Australia were asked about their expectation of students' writing, they answered that the accurate and appropriate use of academic vocabulary is considered very important.

\subsection{Students' Difficulties in Academic Writing}

Writing is a very important method for developing social activities among people (Reid \& Kroll, 1995). For example, if we focused more on expected acts between student-writers and teacher-readers, we can identify that such acts are not meant to inform, persuade, or entertain the teacher but only to demonstrate the performance of the assigned task in a way that is expected by the teacher (Belanoff, 1991; Popken, 1989). Therefore, in this domain, academic writing can be said to be a form of testing performed by students and supervised by professors and teachers. As a result, it could be said that students' assignments could affect their lives, whether positively or negatively, depending on the marks they receive.

Every year, many ESL / EFL students from different countries attend universities in English-speaking countries as well as English-medium universities in non-English speaking countries (e.g. the United Kingdom, the United States of America, Canada, and Japan) to complete their studies (Institute of International Education, 2014). Consequently, there are many different backgrounds of teaching techniques and systems regarding the views and the processes of academic writing process. Such students, according to Flowerdew (1999), face difficulties in academic writing, including, for example, the inability of showing the voice of the writer, the misuse of models in making claims, and localism in interpreting the findings of the studies being read by the students. In addition, Alhojailan (2015) points out that the different systems that students follow in their education affect the way they write.

According to Dudley-Evans (2002) and Cooper and Bikowski (2007), international students encounter many difficulties during the writing process in English-speaking universities. Such students usually lack the techniques needed to write academic assignments, papers, and projects. Therefore, they have to be equipped with academic writing strategies in order to meet the expectations of their lecturers.

In 1992, Casanave and Hubbard conducted a study of the differences between graduate native students (NS) and non-native students (NNS) in terms of the problems they encountered in writing their assignments. They found that NNS students have more problems than the NS students. In general, they noticed that the NNS students have problems in the areas of correctness of punctuation / spelling, accuracy of grammar, appropriateness of grammar, and appropriateness of vocabulary. Interestingly, both NNS and the NS students have a problem with the appropriateness of vocabulary.

\subsection{The Importance of Academic Vocabulary}

Coxhead (2000) defines academic vocabulary as "lexical items [that] occur frequently and uniformly across a wide range of academic material" (p. 218). Coxhead and Nation (2001) highlighted the importance of academic vocabulary for learners of English for academic purposes as follows. First, academic vocabulary can be found in academic texts more than in non-academic texts. Second, academic vocabulary accounts for a substantial number 
of words in academic texts. Third, academic vocabulary is usually not as well-known as the technical vocabulary in a given field, which usually affects second language learners' ability to read academic texts. Finally, unlike technical vocabulary, where the teacher cannot give much feedback to the learner, academic vocabulary gives the teacher the opportunity to help the learners. Laufer (1989) determined that in order for learners to have good comprehension while reading a text written in a second language (L2), they have to know at least around $95 \%$ of the words in that text; since the general service list forms around $80 \%$ of any text, the importance of the academic words (which account for $8 \%$ to $10 \%$ ) in raising the chances of good comprehension is clear.

\subsection{The Role Played by Academic Vocabulary}

There have been several studies seeking to identify the role played by academic vocabulary. Coxhead and Nation (2001), for example, found that academic vocabulary provides a kind of formality and learnedness. Although academic vocabulary is said to pose a challenge for non-native English-speaking students because of its salience and relative low frequency, it fulfils some rhetorical functions in academic texts. For example, it plays a supportive role in constructing the meaning of a text different from that of the technical or discipline-specific words which play a central role (Coxhead, 2000). Nation (2001) indicated that academic vocabulary plays a crucial role in describing and evaluating empirical studies. However, Worthington and Nation (1996) clarified that because of its low frequency in the academic texts, it is unlikely to be learnt incidentally, and, therefore, it is important that academic vocabulary should be taught in an EAP classroom.

\subsection{The Coxhead's Academic Word List (AWL)}

The academic word list (AWL) was created in 2000 by Coxhead. This list is applicable in any discipline. Therefore, all learners, regardless of their field, can benefit from using it. However, the AWL does not include either the technical words expected to be found only in specific discipline or the most 2000 frequent words of English (the General Service List). Coxhead (2000) pointed out that the AWL is limited to academic contexts only. The list consists of 570 word families. Coxhead (2000) relied on three criteria when selecting the words in the AWL:

1). Specialized occurrence: The word families included had to be outside the first 2,000 most frequently occurring words of English, as represented by West's (1953) GSL.

2). Range: A member of a word family had to occur at least 10 times in each of the four main sections of the corpus and in 15 or more of the 28 subject areas.

3). Frequency: Members of a word family had to occur at least 100 times in the Academic Corpus (Coxhead, 2000).

The coverage of the AWL is regarded to be one of its strength in teaching on English for Specific Purposes (ESP) contexts (Coxhead \& Nation, 2001). The AWL and the GSL, according to Coxhead and Nation (2001), cover about $90 \%$ of the words in any academic text. Moreover, the AWL helps in distinguishing EAP from general English and setting out a specific language teaching outline (Hyland \& Tse, 2007). Coxhead (2000) stated that the AWL plays a significant role in writing and in the vocabulary goals for language courses, in helping learners in independent study, and in providing course and material designers with a plan for the information needed when selecting texts and developing learning activities. Moreover, such a list will enable students/readers to become familiar with any academic text. Additionally, this list and similar ones are used to form vocabulary exercises and tests to improve students' recognition of the terms.

\subsection{Research Questions}

Although there has been much research on academic vocabulary in different genres, the student's writing, particularly their assignments, as a genre is still under researched within EAP and ESP contexts (Dudley-Evens, 2002). Therefore, this study examines students' assignments to answer the following research questions:

-Is there a correlation between the use of the academic vocabulary in assignments and the marks the students receive?

-How important is academic vocabulary for successful academic writing from students' point of view?

\section{Methodology}

This study is both quantitative (textual analysis) and qualitative (interview), as such methods will provide more and more varied information that could give precise and comprehensive answers to my research questions.

My study involved 11 students enrolled in studying their master's degree in different programs of the Department of Language and Linguistics of a British university. I decided to include graduate students and not 
undergraduate ones because at that level the students have been exposed to academic life more than the undergraduate students have, which means they have a very high level of spoken and written English. The students come from the following countries: the United Kingdom, Taiwan, Syria, Kuwait, Japan, Bahrain, Cyprus, and Saudi Arabia.

After the informants signed the consent form, I arranged meetings with five of the participants for interviews; each participant was interviewed separately. Rubin and Rubin (1995) stated that the qualitative interview enables the researcher to learn what others feel and think of their worlds. In addition, they continue, the researcher can understand the experiences even if he/she did not experience them. A semi-structured interview will give the chance to introduce the topic of discussion to the interviewees and guide the discussion to answer the research questions. Miles and Huberman (1994) pointed out that the outcome of such an approach is more reliable since the data are given in detail, which will enable the researcher to lay solid ground for the study. The questions of the interview were prepared in advance and freedom was given to the interviewees to express their opinions openly. The interviews lasted between 30 to 45 minutes each and were audio-recorded. The interviews were mainly conducted in English.

For the data submitted by the students comprised one or more of their assignments for one or more of the MA courses they had enrolled in. The assignments were sent to me electronically. The purpose of receiving an electronic version is to be able to apply some programs (i.e., lexical tutor) to them. Every assignment received a filename which incorporated information such as the student ID, the mark, and the course code. The assignments' length was 3000 words with a $( \pm 15 \%)$. The marks are interpreted as follows: less than 50 as fail, 50-59 as pass, 60-69 as merit, and finally 70 and above as distinction. The assignments came from both genders and from different courses, including applied linguistics, language teaching, language testing, teaching writing in ESL / EFL, foundation of English for specific purposes, and qualitative methodology in English language teaching.

\section{Results}

\subsection{Academic Vocabulary in the Students' Assignments}

The 23 assignments as a whole form a corpus of 66,231 words with an average of 2879.6 words for each assignment. Academic vocabulary accounts for $9.97 \%$ of the whole corpus. The percentage of AWL items in my study is the lowest among the studies conducted thus far focusing on the percentage of AWL items in the same discipline. For example, in Cobb and Horst's study (2002), the percentage of AWL items is $12.60 \%$, in Chung and Nation's study (2003)17.4\%, and finally in Vongpumivitch, Huang and Chang's study (2009)11.17\%. Table 1 provides more information about these studies and their percentages of AWL items.

Table 1 . The findings of this study and of other studies in the same discipline by percentage of AWL items

\begin{tabular}{llll}
\hline Researcher(s) & Discipline & Kind of corpus & Percentage AWL items \\
\hline Cobb and Horst (2002) & Linguistics & Texts & $12.60 \%$ \\
Chung and Nation (2003) & Applied linguistics & Books & $17.40 \%$ \\
$\begin{array}{l}\text { Vongpumivitch, Huang and Chang } \\
(2009)\end{array}$ & Applied linguistics & Research articles & $11.17 \%$ \\
& Applied linguistics, & MA & \multicolumn{2}{c}{ students' } \\
My study & Linguistics, and & assignments & \\
& ELT & & \\
\hline
\end{tabular}

Academic vocabulary appeared in the assignments 6608 times. Of the 570 words that Coxhead identified as academic words in her list, 465 words appeared in the students' assignments, which is very close to the number of identified AWL items that appeared in Vongpumivitch et al. (2009), which is 475 words.

\subsection{The Correlation Between the Use of Academic Vocabulary in the Assignments and the Marks the Students Get}

In order to test the correlations between the use of the academic words in the students' assignments and the marks the students received, Pearson $r$ correlation coefficient were calculated as shown in Table 2. 
Table 2. Correlation test

\begin{tabular}{lll}
\hline & Mark & AWL \\
\hline Mark Pearson Correlation & 1 & 0.195 \\
Sig. (2-tailed) & & 0.374 \\
N & 23 & 23 \\
AWL Pearson Correlation & 0.195 & 1 \\
Sig. (2-tailed) & 0.374 & \\
N & 23 & 23 \\
\hline
\end{tabular}

As can be seen in Table 2, Pearson's correlation coefficients indicate that the correlation between the use of academic vocabulary in the students' assignments and the marks they received is weak since the value of $r$ is 0.195 , which is closer to 0 than to 1 .

In addition, Figure 1 indicates clearly that there is no evident relation between the trend of academic vocabulary in the students' assignments and the trend of the students' marks, whether positive or negative.

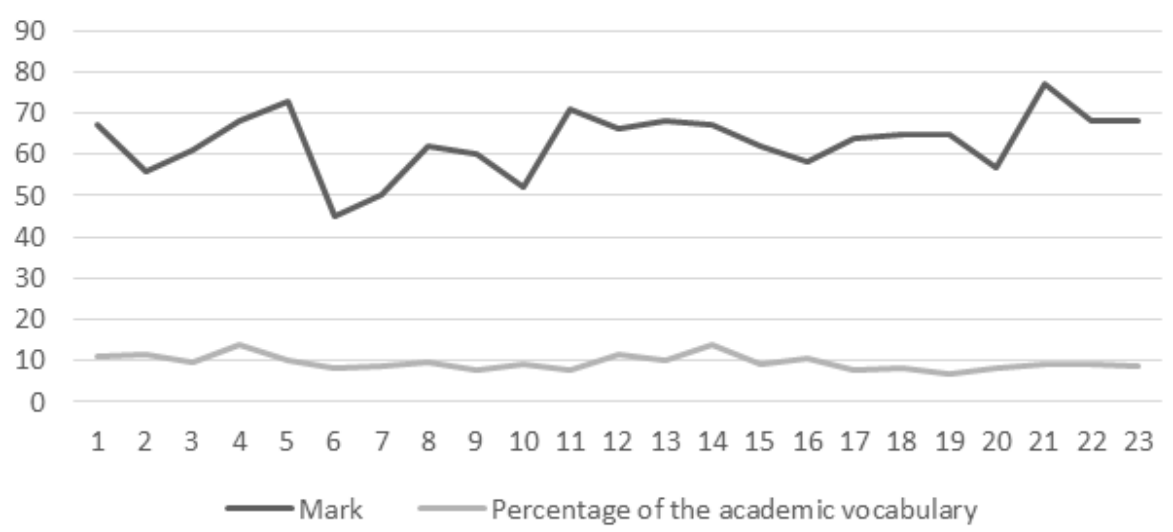

Figure 1. The correlation between the percentage of academic vocabulary in the students' assignments and the students' marks

Furthermore, both Table 3, which the assignments by mark, and Table 4, which orders the assignments by percentage of academic vocabulary, demonstrates no correlation between the use of academic vocabulary in the students' assignments and the students' marks. For example, the highest mark in this corpus is 77 and the lowest one is 45 , which papers contain neither the highest nor the lowest percentages of academic vocabulary. Conversely, the highest percentage of academic vocabulary is $13.88 \%$ and the lowest is $6.83 \%$, neither of which received the highest or lowest mark.

Table 3. Assignments ordered by mark

\begin{tabular}{ll}
\hline Mark & Amount of academic vocabulary \\
\hline $\mathbf{7 7}$ & $9.31 \%$ \\
$\mathbf{7 3}$ & $10.07 \%$ \\
$\mathbf{7 1}$ & $7.65 \%$ \\
$\mathbf{6 8}$ & $13.76 \%$ \\
$\mathbf{6 8}$ & $10.14 \%$ \\
$\mathbf{6 8}$ & $8.74 \%$ \\
$\mathbf{6 8}$ & $9.31 \%$ \\
\hline
\end{tabular}




\begin{tabular}{ll}
\hline $\mathbf{6 7}$ & $13.88 \%$ \\
$\mathbf{6 7}$ & $11.03 \%$ \\
$\mathbf{6 6}$ & $11.4 \%$ \\
$\mathbf{6 5}$ & $8.06 \%$ \\
$\mathbf{6 5}$ & $6.83 \%$ \\
$\mathbf{6 4}$ & $7.88 \%$ \\
$\mathbf{6 2}$ & $9.48 \%$ \\
$\mathbf{6 2}$ & $9 \%$ \\
$\mathbf{6 1}$ & $9.88 \%$ \\
$\mathbf{6 0}$ & $7.67 \%$ \\
$\mathbf{5 8}$ & $10.51 \%$ \\
$\mathbf{5 7}$ & $8.01 \%$ \\
$\mathbf{5 6}$ & $11.53 \%$ \\
$\mathbf{5 2}$ & $8.98 \%$ \\
$\mathbf{5 0}$ & $8.63 \%$ \\
$\mathbf{4 5}$ & $8.38 \%$ \\
\hline
\end{tabular}

Table 4. Assignments ordered by percentage of academic vocabulary

\begin{tabular}{ll}
\hline Percentage of academic vocabulary & Mark \\
\hline $\mathbf{1 3 . 8 8 \%}$ & 67 \\
$\mathbf{1 3 . 7 6 \%}$ & 68 \\
$\mathbf{1 1 . 5 3 \%}$ & 56 \\
$\mathbf{1 1 . 0 4 \%}$ & 66 \\
$\mathbf{1 1 . 0 3 \%}$ & 67 \\
$\mathbf{1 0 . 5 1 \%}$ & 58 \\
$\mathbf{1 0 . 1 4 \%}$ & 68 \\
$\mathbf{1 0 . 7 \%}$ & 73 \\
$\mathbf{9 . 8 8 \%}$ & 61 \\
$\mathbf{9 . 4 8 \%}$ & 62 \\
$\mathbf{9 . 3 1 \%}$ & 77 \\
$\mathbf{9 . 3 1 \%}$ & 68 \\
$\mathbf{9 \%}$ & 62 \\
$\mathbf{8 . 9 8 \%}$ & 52 \\
$\mathbf{8 . 7 4 \%}$ & 68 \\
$\mathbf{8 . 6 3 \%}$ & 50 \\
$\mathbf{8 . 3 8 \%}$ & 45 \\
$\mathbf{8 . 0 6 \%}$ & 65 \\
$\mathbf{8 . 0 1 \%}$ & 57 \\
$\mathbf{7 . 8 8 \%}$ & 64 \\
$\mathbf{7 . 7 6 \%}$ & 60 \\
$\mathbf{7 . 6 5 \%}$ & 71 \\
$\mathbf{6 . 8 3 \%}$ & 65 \\
\hline
\end{tabular}

However, four of the interviewees $(80 \%)$ expressed that they put heavy stress on the presence of academic vocabulary in the assignments and accentuated the correlation between the use of academic vocabulary and the marks they received. They believe that the more academic vocabulary in an assignment, the higher the mark that they can expect to receive. 


\subsection{Students' Understanding of the Academic Vocabulary}

Despite the fact that only one of the informants knew about the AWL, most of the students' definitions of 'academic vocabulary' were rather circular. For example, one of the informants mentioned that "it is the word that we expect to find in the academic books" (Robin, Interview Transcript, p. 4). Another informant stated that "it is the word that is highly expected to hear at the university" (Sophia, Interview Transcript, p. 7). A third student referred to it as "the language that teachers and professors expects their students to use" (Mark, Interview Transcript, p. 13).

Moreover, out of 25 words the informants said when asked to give 5 academic words; 15 were from the AWL. Additionally, when the informants were asked to select the academic words from a list of words containing both academic and non-academic words, $76.6 \%$ of their choices were correct (the words the students chose were from the AWL).

\subsection{Students' Attitudes Towards Using Academic Vocabulary}

With the exception of the English native speaker, all the interviewees have been studying English for periods ranfing from 12 years to 17 years. The answers of the interviewees clearly show that the use of academic vocabulary forms a great part of their thinking when writing their assignments.

The students listed the following as the criteria affecting their marks:

1)- The construction of the assignment

2)- The usage of the language (grammar and vocabulary)

3)- The ideas of the assignment and how they are developed

4)- Understanding what is required in the assignment

Surprisingly, not all the interviewees attach equal importance to academic vocabulary. On the one hand, $80 \%$ of the interviewees considered it is essential to include many academic words in their assignments for several different reasons, namely: 1) most academic books do contain academic words, 2) having such words will help students while writing the assignments, 3) being linguists force students to use academic words, 4) to show the reader that they read a lot and they have rich vocabularies. On the other hand, $20 \%$ of the interviewees mentioned that they include some academic words but not many. The justification provided for this attitude is that the important factor in writing the assignment is to deliver the ideas correctly, not to show off the words used in the assignments.

\subsection{How do Students Make Their Assignments Academic?}

Concerning the ways and methods the interviewees use and follow in order to make their assignments academic, they listed the following:

University-related:

1)- Using the style learned in the pre-sessional and in-sessional courses.

2)- Using some of the academic words used by professors.

Not university-related:

1)- Imitating other writers' structures and words.

2)- Including some academic words.

3)- Reading books that focus mainly on teaching academic vocabulary.

4)- Listening to the $\mathrm{BBC}$ in the radio.

\subsection{Strategies Used in Choosing the Academic Vocabulary}

The interviewees listed several strategies they usually follow to choose academic vocabulary. For example, they use dictionaries, whether paper, online, or electronic ones, to ensure that the word they are using is an academic one. Additionally, the synonym feature, which can be found in the Word, was mentioned as one of the means of identifying academic vocabulary. Interestingly, one of the interviewees referred to his English background, which provides him with a good body of words; therefore, he does not have to rely on a dictionary or any other means to ensure that the vocabulary he is using is academic.

\section{Discussion}

A likely reason that this study showed the lowest percentage of used academic vocabulary of the studies of this 
topic is that the sample in this study comprises students' assignments, indicating that the students are not at as high a level of professionalism in academic writing as the samples on the other studies.

The reason that $80 \%$ of the interviewees put a strong emphasis on using academic vocabulary in their assignments could be attributed to the students' majors, which require them to write the assignments mostly using words, unlike other majors (e.g. engineering, computer science, and chemistry) that require a heavier use of numbers and graphs in their assignments.

The students listed some criteria that affected their marks on their assignments. Most of the informants considered vocabulary one of the factors that could affect their marks, and viewed the inappropriate usage of certain words in the assignments as one of the reasons for the differences between the highest and lowest marks, which is similar to the findings of Bush et al.'s study (1996). Additionally, nativeness is a possible reason that only the native speaker of English claimed that he does not try to include many academic words in his assignments, which shows that students who are non-native speakers of English still consider the use of academic vocabulary as a major issue that could affect their academic lives, whether positively or negatively.

The students' definitions and choices of academic words might indicate that they are, to some degree, aware of the notion of academic vocabulary. The two methods, which relate to the university, that the interviewees use to make their assignments academic might reflect the fact that some cultures consider the teacher as the only source of knowledge (Grami, 2012). Therefore, students from such backgrounds should be directed to explore other sources for learning academic vocabulary.

\section{Conclusion}

As students are increasingly required to use academic vocabulary while in college, this research was performed to determine whether there was a statistical correlation between the use of academic vocabulary in tasks and the marks acquired by graduate students using a purposeful sample of graduate students $(n=11)$. The findings of the study show that the correlation between the use of the academic words and the marks the students received was weak. This, of course, suggests that students, course designers, professors, and pre-sessional and in-sessional course directors should not concentrate only on learning academic vocabulary but that, as a part of that, other factors should receive attention in the educating process, such as: punctuation, rhetorical moves, hypothesizing, citation, showing the voice of the writer, and paraphrasing.

\section{References}

Alhojailan, A. I. (2015). Perceptions of academic writing by some Saudi graduate students studying in American universities (Doctoral dissertation). Retrieved from https://search-proquest-com.sdl.idm.oclc.org/docview/ 1830467924 ? accountid $=142908$

Belanoff, P. (1991). The Myths of assessment. Journal of Basic Writing, 10, 54-66.

Bush, D., Cadman, C., de Lacey, P., Simmons, D., \& Thurstun, J. (1996). Expectations of academic writing at Australian universities. Paper presented at the First National Conference on Tertiary Literacy: Research and Practice. Melbourne. https://doi.org/10.1016/S0889-4906(97)00013-6

Casanave, C., \& Hubbard, P. (1992). The writing assignments and writing problems of doctoral students: Faculty perceptions, pedagogical issues, and needed research. English for Specific Purposes, 11, 33-49. https://doi.org/10.1016/0889-4906(92)90005-U

Chung, M., \& Nation, P. (2003). Technical vocabulary in specialized texts. Reading in a Foreign Language, 15(2), 103-116.

Cobb, T., \& Horst, M. (2001). Reading academic English: Carrying learners across the lexical threshold. In J. Flowerdew, \& M. Peacock (Eds.), Research Perspectives on English for Academic Purposes (pp. 315-329). Cambridge: Cambridge University Press. https://doi.org/10.1017/cbo9781139524766.024

Cooper, A., \& Bikowski, D. (2007). Writing at the Graduate Level: What Tasks do Professors Actually Require? Journal of English for Academic Purposes, 6, 206-21. https://doi.org/10.1016/j.jeap.2007.09.008

Coxhead, A. (2000). A new academic word list. TESOL Quarterly, 34, 213-238. https://doi.org/10.2307/3587951

Coxhead, A., \& Nation, P. (2001). The specialized vocabulary of English for Academic Purposes. In J. Flowerdew, \& M. Peacock (Eds.) Research Perspectives on English for Academic Purposes (pp. 252-267). Cambridge: Cambridge University Press. https://doi.org/10.1017/cbo9781139524766.020

Dudley-Evans, T. (2002). The teaching of the academic essay: Is a genre approach possible? In A. Johns (Ed.) Genre in the classroom. Multiple perspectives (pp. 225-235). Mahwah: Lawrence Erlbaum. 
Flowerdew, J. (1999). Problems in writing for scholarly publication in English: The case of Hong Kong. Journal of Second Language Writing, 8, 123-145. https://doi.org/10.1016/S1060-3743(99)80125-8

Grami, G. M. (2012). Are Learner-Centred Approaches the Answer to Saudi Language Classes' Shortcomings ? Annual Review of Education, Communication and Language Sciences, 9, 6-16.

Hyland, K., \& Tse, P. (2007). Is there an "academic vocabulary"? TESOL Quarterly, 41, 235-253. https://doi.org/10.1002/j.1545-7249.2007.tb00058.x

Institute of International Education. (2014). Project Atlas: Trends and global data 2014. Retrieved from http://www.iie.org/Research-and-Publications/Project-Atlas

Laufer, B. (1989). What percentage of text-lexis is essential for comprehension? In C. Lauren, \& M. Nordman (Eds.), Special Language: From Humans Thinking to Thinking Machines (pp. 316-323). Clevedon: Multilingual Matters.

Laufer, B., \& Nation, P. (1999). A vocabulary-size test of controlled productive ability. Language Testing, 16(1), 33-51.

Maiguashca, R. (1993). Teaching and learning vocabulary in a second language: Past, present, and future directions. Canadian Modern Language Review, 50, 83-100. https://doi.org/10.3138/cmlr.50.1.83

Miles, M. B., \& Huberman, A. M. (1994). Qualitative Data Analysis: An Expanded Sourcebook (2nd ed.). Thousand Oaks: Sage Publication.

Ming-tzu, K., \& Nation, P. (2004). Word Meaning in Academic English: Homography in the Academic Word List. Applied Linguistics, 25(3), 291-314. https://doi.org/10.1093/applin/25.3.291

Nation, P. (2001). Learning Vocabulary in Another Language. Cambridge University Press. https://doi.org/10.1017/CBO9781139858656

Popken, R. L. (1989). Essay exams and papers: A contextual comparison. Journal of Teaching Writing, 8, 51-65.

Reid, J., \& Kroll, B. (1995). Designing and Assessing Effective Classroom Writing Assignments for NES and ES1 Students. Journal of Second Language Writing, 4(I), 17-41. https://doi.org/10.1016/1060-3743(95) 90021-7

Rubin, H., \& Rubin, I. (1995). Qualitative interviewing: The art of hearing data. Thousand Oaks. Sage Publication.

Swales, J. (1990). Genre Analysis: English in Academic and Research Settings. Cambridge: Cambridge University Press. https://doi.org/10.1075/z.184.513swa

Vongpumivitch, V., Huang, J., \& Chang, Y. (2009). Frequency analysis of the words in the Academic Word List (AWL) and non-AWL content words in applied linguistics research papers. English for Specific Purposes, 28, 33-41. https://doi.org/10.1016/j.esp.2008.08.003

West, M. (1953). A General Service List of English Words. Longman, London.

Xue, G. Y., \& Nation, P. (1984). A University Word List. Language Learning and Communication, 3, 215-229.

\section{Copyrights}

Copyright for this article is retained by the author(s), with first publication rights granted to the journal.

This is an open-access article distributed under the terms and conditions of the Creative Commons Attribution license (http://creativecommons.org/licenses/by/4.0/). 